\title{
Reabilitação de paciente pós câncer de cabeça e pescoço com overdenture inferior sobre dentes: relato de caso
}

\author{
Rehabilitation of a patient after head and neck cancer with inferior overdenture on teeth: a case \\ report \\ Rehabilitación de un paciente tras un cáncer de cabeza y cuello con sobredentadura inferior en los \\ dientes: reporte de un caso
}

Recebido: 02/06/2021 | Revisado: 14/06/2021 | Aceito: 16/06/2021 | Publicado: 30/06/2021

\author{
Camila de Carvalho Almança Lopes \\ ORCID: https://orcid.org/0000-0001-9313-9818 \\ Universidade Federal de Uberlândia, Brasil \\ E-mail: camila.calopes@gmail.com \\ Allyne Jorcelino Daloia de Carvalho \\ ORCID: https://orcid.org/0000-0002-9231-0895 \\ Universidade Federal de Uberlândia, Brasil \\ E-mail: allyne.carvalho@hotmail.com \\ Morgana Guilherme de Castro Silverio \\ ORCID: https://orcid.org/0000-0002-0352-7946 \\ Universidade Federal de Uberlândia, Brasil \\ E-mail: morgana.guilherme35@gmail.com \\ Luiz Carlos Gonçalves \\ ORCID: https://orcid.org/0000-0003-0577-8076 \\ Universidade Federal de Uberlândia, Brasil \\ E-mail: luizcgrr@gmail.com \\ Paulo Cézar Simamoto Júnior \\ ORCID: https://orcid.org/0000-0001-6087-9721 \\ Universidade Federal de Uberlândia, Brasil \\ E-mail: psimamoto@gmail.com \\ Veridiana Resende Novais \\ ORCID: https://orcid.org/0000-0001-9017-2946 \\ Universidade Federal de Uberlândia, Brasil \\ E-mail: veridianaresende@hotmail.com
}

\begin{abstract}
Resumo
A radioterapia é uma das formas de tratamento do câncer e, embora seja um método direcionado às células tumorais, causa diversos danos à cavidade oral dos pacientes diagnosticados com câncer em cabeça e pescoço. A cárie relacionada à radiação, diminuição da salivação e risco à osteorradionecrose tornam o tratamento reabilitador destes pacientes bastante desafiador. Deste modo, o objetivo deste artigo é relatar o caso clínico de um paciente pósradioterápico, devido a câncer na região de cabeça e pescoço, que apresentava falta de retenção e estabilidade da prótese parcial removível inferior devido à falta de suporte em função da destruição coronária pela cárie relacionada à radiação.A reabilitação foi realizada com a confecção de prótese total convencional superior e prótese overdenture inferior, utilizando as raízes dentais dos caninos inferiores como suportes e uso de sistema de retenção de precisão. No geral, a prótese total convencional inferior pode apresentar comprometimento de retenção e estabilidade e, em pacientes radioterápicos, esta condição é agravada em decorrência das consequências da radioterapia na cavidade oral, afetando diretamente a capacidade mastigatória, fala e estética, além de impactar a qualidade de vida do paciente. O risco à osterorradionecrose pode contraindicar a realização de exodontias e instalação de implantes osteointegrados, sendo, portanto, a manutenção de raízes dentais como suporte para próteses do tipo overdenture uma alternativa interessante para a reabilitação destes pacientes. O acompanhamento periódico do paciente radioterápico é importante para evitar possíveis insucessos do tratamento reabilitador.
\end{abstract}

Palavras-chave: Câncer; Prótese overdenture; Radioterapia; Reabilitação oral.

\section{Abstract}

Radiotherapy is one of the forms of cancer treatment and, although it is a method directed at tumor cells, it causes several damages to the oral cavity of patients diagnosed with head and neck cancer. Caries related to radiation, decreased salivation and the risk of osteoradionecrosis make the rehabilitative treatment of these patients quite challenging. Thus, the objective of this article is to report the clinical outcome of a post-radiation therapy patient due 
to cancer in the head and neck region who presented lack of retention and stability of the lower removable partial prosthesis due to the lack of support in function of coronary destruction by radiation-related caries. The rehabilitation was carried out with the preparation of a conventional upper denture and a lower overdenture prosthesis, using the dental roots of the lower canines as supports and use of precision restraint system. In general, the lower conventional full denture may have compromised retention and stability and in radiotherapy patients this condition is aggravated due to the consequences of radiotherapy in the oral cavity, directly affecting the masticatory, speech and aesthetic capacity, in addition to impacting in the patient's quality of life. The risk of osteoradionecrosis may contraindicate the performance of extractions and installation of osteointegrated implants and therefore the maintenance of dental roots as a support for overdenture prostheses is an interesting alternative for the rehabilitation of these patients. Periodic follow-up of the radiotherapy patient is very important to avoid possible failures of the rehabilitation treatment.

Keywords: Cancer; Overdenture prosthesis; Radiotherapy; Oral rehabilitation.

\section{Resumen}

La radioterapia es una de las formas de tratamiento del cáncer y, aunque es un metodo dirigido a las células tumorales, causa varios daños en la cavidad bucal de los pacientes diagnosticados com cáncer de cabeza y cuello. La caries relacionada con la radiación, la disminución de la salivación y el riesgo de osteorradionecrosis hacen que el tratamiento rehabilitador de estos pacientes sea bastante desafiante. Así, el objetivo de este artículo es reportar el caso clínico de un paciente postratamiento de radioterapia, por cáncer em la región de cabeza y cuello quien se presentó la falta de retención y estabilidad de la prótesis parcial removible inferior por falta de apoyo em función de la destrucción coronaria por caries relacionada con la radiación. La rehabilitación se llevó a cabo con la preparación de una dentadura completa superior convencional y una sobredentadura inferior, utilizando como soporte las raíces dentales de los caninos inferiores y uso de sistema de sujeción de precisión. En general, la dentadura completa convencional inferior puede presentar compromiso de retención y estabilidad y, en pacientes con radioterapia, esta condición se agrava por las consecuencias de la radioterapia en la cavidad bucal, afectando directamente la capacidad masticatoria, fonográfica y estética, además de impactar la calidad de vida del paciente. El riesgo de osteorradionecrosis puede contraindicar la realización de extracciones y instalación de implantes osteointegrados, por lo que el mantenimiento de las raíces dentales como soporte de las prótesis sobredentaduras es una alternativa interesante para la rehabilitación de estos pacientes. La monitorización periódica del paciente en radioterapia es muy importante para evitar posibles fracasos del tratamiento rehabilitador.

Palabras clave: Cáncer; Prótesis de sobredentadura; Radioterapia; Rehabilitación oral.

\section{Introdução}

As doenças crônicas matam 41 milhões de pessoas a cada ano por todo o mundo, e o câncer é responsável por $22 \%$ de todas as mortes por estas doenças (World Health Organization, 2020). O aumento da incidência e mortalidade do câncer está associado ao envelhecimento e crescimento da população e com mudanças na ocorrência e distribuição de seus fatores de risco (Bray et al., 2018). Os tumores malignos nas regiões de cabeça e pescoço compreendem, atualmente, o quinto tipo de câncer mais frequente em homens e décimo primeiro em mulheres, no Brasil (INCA, 2019). A radioterapia é uma das formas de tratamento que destrói células cancerígenas por meio da radiação ionizante (Bueno et al., 2012). Embora haja a preservação das estruturas dos tecidos, a radioterapia acarreta inúmeras reações adversas que afetam a qualidade de vida dos pacientes (Spetch, 2002). Estes efeitos adversos incluem mucosite (Montserrat et al., 2006), dor e distúrbios sensoriais, alteração das glândulas salivares, disgeusia, ocorrência de doenças oportunistas como a candidose, aumento da suscetibilidade à cárie dentária e aumento do risco à osteorradionecrose (Sroussi et al., 2017).

A osteorradionecrose e a cárie relacionada a radiação ionizante são considerados efeitos adversos tardios (Bhandari et al., 2020). Clinicamente, a cárie relacionada à radiação ionizante difere-se da cárie convencional por apresentar progressão mais rápida e agressiva (Moore et al., 2020). Seu surgimento está relacionado à alterações nas propriedades químicas, mecânicas e biológicas da estrutura dental decorrentes da radiação (Gonçalves et al., 2014; Lopes et al., 2018; Lopes et al., 2021; Miranda et al., 2018; Miranda et al., 2021; Reed et al., 2015; Rodrigues et al., 2018) associadas a fatores indiretos da radiação, como danos às glândulas salivares, resultando em hipossalivação e xerostomia, distúrbios na microbiota oral, presença de mucosites e dificuldades de higienização (Moore et al., 2020; Muller et al., 2019). É caracterizada por delaminações do esmalte, seguidas por trincas e fraturas que podem levar à amputação total das coroas dos dentes, expondo o remanescente radicular ao meio oral (Palmier et al., 2020). Já o osso, torna-se mais hipóxico e hipovascular após a 
radioterapia, o que aumenta o risco à osteorradionecrose (Chronopoulos et al., 2018). Esta condição consiste na necrose isquêmica do osso, na maioria das vezes desencadeada por procedimentos invasivos, como cirurgias e extrações dentárias, sendo um fator importante a ser considerado no processo reabilitador do indivíduo após o tratamento (Chronopoulos et al., 2018; Jham \& Freire 2006).

A reabilitação oral de pacientes que passaram por radioterapia envolve uma série de cuidados devido às alterações intraorais decorrentes do tratamento. A hipossalivação resulta em aumento da viscosidade e diminuição do fluxo salivar, os quais são condições primordiais para a retenção de próteses removíveis. Além do mais, alterações endoteliais nos tecidos moles favorecem o surgimento de úlceras traumáticas, que podem se agravar com risco de desenvolvimento de osteoradionecrose (Schoen et al., 2007). Neste contexto, para uma melhor retenção e estabilidade das próteses removíveis, pode-se optar por próteses do tipo overdenture retidas por dentes que se encontram presentes na cavidade oral.

As condições bucais decorrentes da radioterapia em região de cabeça e pescoço tornam a reabilitação oral destes pacientes complexa, desta forma, há poucos trabalhos publicados sobre essa temática. Relatar e discutir casos clínicos de reabilitações de pacientes irradiados é muito relevante, sendo benéfico para o conhecimento de demais profissionais que atendem este grupo de pacientes. Deste modo, o objetivo deste artigo é relatar a reabilitação de um paciente irradiado, devido a câncer na região de cabeça e pescoço, que se queixava da falta de retenção e estabilidade da prótese parcial removível inferior. Foram confeccionadas uma prótese total convencional maxilar e uma prótese overdenture mandibular, na qual dois caninos inferiores foram utilizados como dentes suportes, associados com sistema de anel de retenção (Equator). Este artigo discute as dificuldades e aspectos importantes sobre a reabilitação oral deste grupo de pacientes.

\section{Metodologia}

Este trabalho constitui um relato de caso clínico, cujo caráter é descritivo e qualitativo. Um estudo de caso deve apresentar uma descrição e análise, o mais detalhada possível, de uma situação clínica particular, que a torne diferencial (Pereira et al., 2018). Desta forma, este caso relatado possui riqueza de descrição e informações precisas a cerca das condutas clínicas e técnicas que foram executas. O paciente frequentava o programa de extensão de Suporte Odontológico Preventivo e Restaurador ao Paciente portador de Neoplasia Maligna sob Tratamento Oncológico (SOPRO), vinculada ao Programa de Cuidados Especiais a Doenças Estomatológicas (Procede) em parceria com o projeto de extensão Overdenture para desdentados totais na geriatria da Escola Técnica de Saúde da Universidade Federal de Uberlândia, e após compreender e concordar com todo o plano de tratamento proposto, assinou o Termo de Consentimento Livre e Esclarecido. Foram seguidos todos os princípios éticos envolvendo pesquisas médicas em seres humanos, contidos na Declaração de Helsinque.

Neste trabalho, foi realizada a reabilitação oral, por meio de prótese total removível superior e prótese overdenture inferior, de um paciente após tratamento radioterápico, devido à um câncer em região de cabeça e pescoço. Para o embasamento científico do trabalho, foram feitas buscas na literatura nas bases de dados Scielo e PubMed, sem restrições de ano, utilizando as seguintes palavras-chave: "Oral Cancer"; "Oral Rehabilitation"; "Overdenture"; "Radiotherapy".

\section{Relato de Caso}

Paciente do gênero masculino, leucoderma, 79 anos, compareceu ao atendimento de Suporte Odontológico Preventivo e Restaurador ao Paciente portador de Neoplasia Maligna sob Tratamento Oncológico (SOPRO), vinculado ao Programa de Cuidados Especiais a Doenças Estomatológicas (Procede) da Universidade Federal de Uberlândia para acompanhamento odontológico pós-radioterápico devido a carcinoma espinocelular de amígdala. A queixa do paciente era de falta de retenção e estabilidade da sua prótese parcial removível inferior e dor devido a úlceras traumáticas relacionadas à hipossalivação decorrente da radioterapia. O paciente havia passado por cirurgia para remoção da neoplasia, realizado 40 sessões de 
radioterapia e ainda 8 sessões de quimioterapia. Observou-se uma assimetria facial devido a excisão cirúrgica da neoplasia (Figura 1-A). Ao exame clínico intraoral, notou-se que o paciente apresentava maxila totalmente edêntula, com rebordo alveolar de formato oval, mucosa de resiliência média na região posterior da maxila e flácida na região anterior, com coloração avermelhada e uso de prótese total mucossuportada. Na mandíbula, estavam presentes a raiz residual do dente 33 e o elemento dental 43, com extensas restaurações em resina composta, lesões de cárie relacionada à radiação, acúmulo de placa bacteriana e gengivite. Havia ainda perda óssea extensiva na região posterior da mandíbula, mucosa de resiliência média e uso de uma prótese parcial removível mandibular com extensão incorreta e com pouca retenção (Figura 1-B,C,D,E). O plano de tratamento definido ao paciente foi: adequação do meio bucal por meio da remoção de biofilme e cálculos dentais, remoção de tecido cariado e restauração, orientações de higiene bucal, tratamento endodôntico nos dois elementos dentais inferiores, confecção de nova prótese total maxilar e uma overdenture mandibular sobre raízes.

Figura 1 - Aspecto inicial do paciente. A) Vista frontal inicial do paciente sorrindo. B) Foto intraoral do paciente com as próteses em posição; C) Foto intraoral da maxila; D) Foto intraoral do elemento dental 43, evidenciando extensa destruição pela cárie relacionada a irradiação; E) Foto intraoral dos dentes remanescentes inferiores.

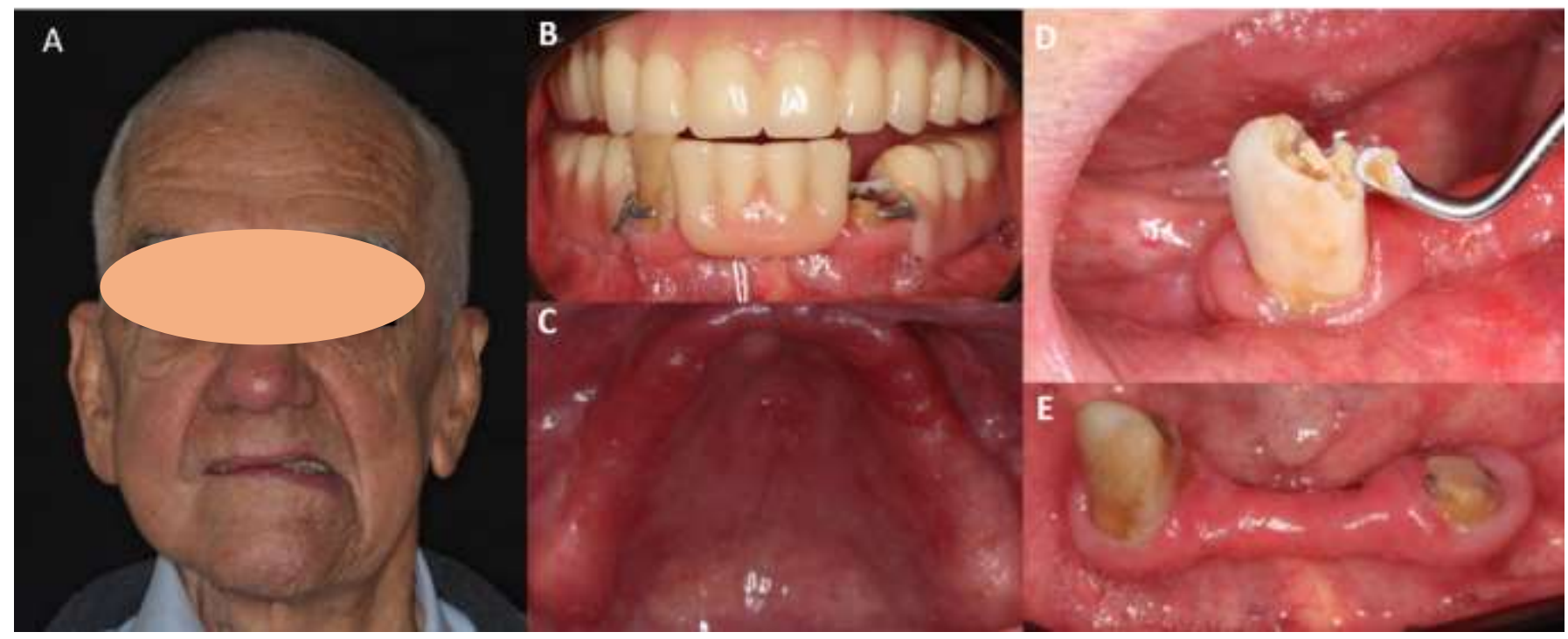

Fonte: Autores.

Com o tratamento endodôntico concluído, no último atendimento a coroa dental do 43 foi seccionada e os remanescentes dentários 33 e 43 foram desgastados $2 \mathrm{~mm}$ acima da margem gengival com ponta diamantada cilíndrica, para melhor acomodação das raízes sob a prótese parcial removível e seladas com resina composta fotopolimerizável (Resina Filtek Z350XT - 3M ESPE, St. Paul, MN, EUA). Foi realizado reparo na prótese parcial removível inferior, removendo os braços de ação dos grampos $\mathrm{T}$, acrescentando-se dentes de estoque na região dos dentes 33 e 43, além da realização de um reembasamento imediato com material soft, tornando-a uma prótese removível total provisória (Figura 2). 
Figura 2 - A) Tratamento endodôntico dos dentes 33 e 43; B) Secção da coroa do 43; C) desgaste de ambos os elementos dentais para melhor acomodação das raízes sob a prótese parcial removível; D) Vista oclusal da PPR provisória inferior após acréscimo dos dentes 33 e 43 de estoque; E) Vista da base da PPR provisória inferior reembasada.

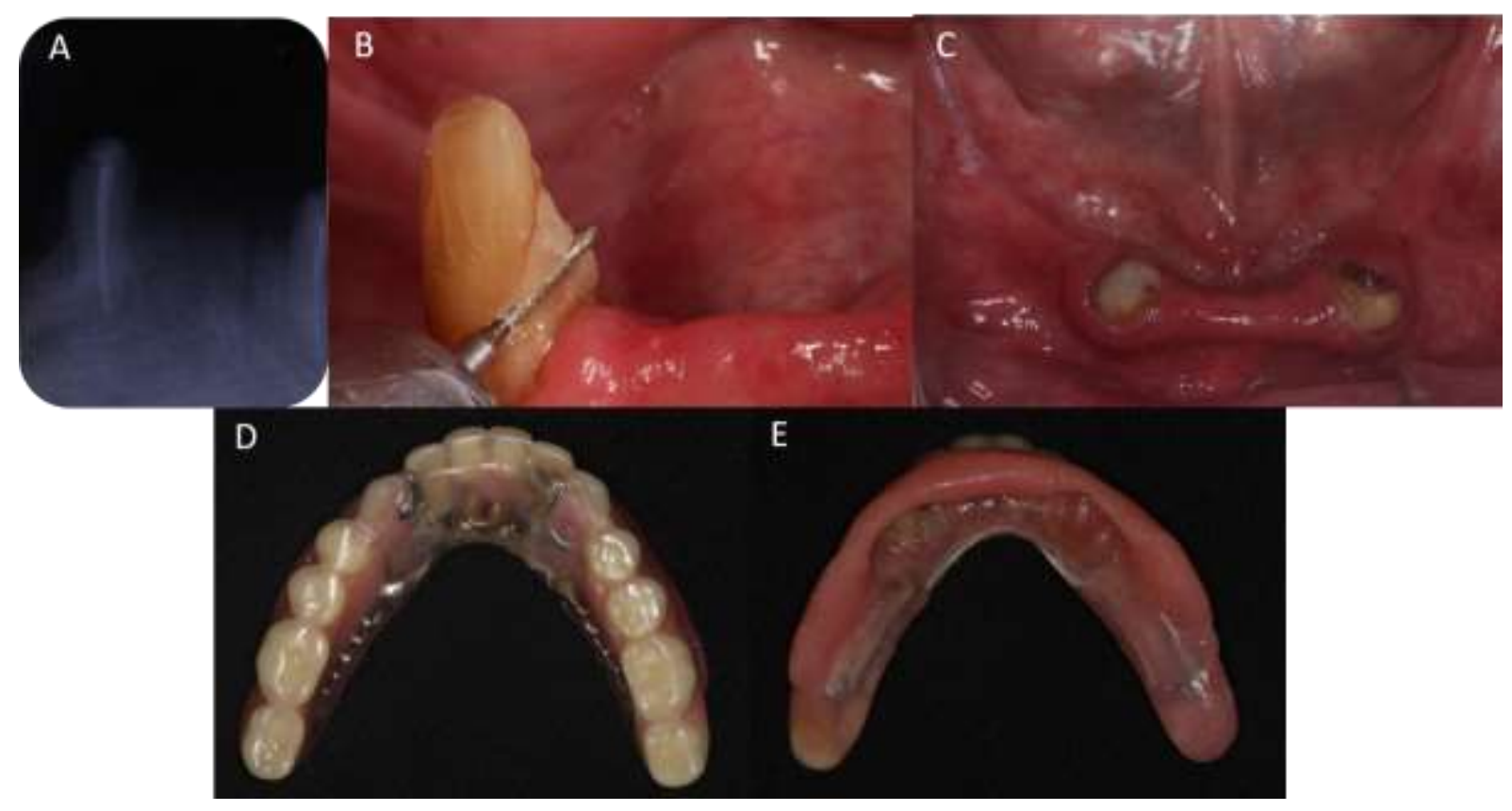

Fonte: Autores.

Na sessão seguinte, foram realizadas as moldagens anatômicas superior e inferior com moldeiras de estoque do tipo HDR (Tecnodent Indústria e Comércio Ltda, Indaiatuba, SP, Brasil) individualizadas com cera periférica e hidrocolóide irreversível (New Print - Dencril Produtos Odontológicos, Pirassununga, SP, Brasil). Após a moldagem, os moldes anatômicos foram lavados em água corrente e foi feita a desinfecção com hipoclorito de sódio 1\% (Figura 3). Em seguida, foram confeccionados os modelos anatômicos em gesso pedra tipo III (Asfer Indústria Química Ltda, São Caetano do Sul, SP, Brasil) para estudo da anatomia de interesse protético, delimitação da área basal e confecção das moldeiras individuais. Após a delimitação da área chapeável e o alívio das áreas retentivas com cera 7 rosa (Lysanda - Lysanda Prod. Odontológicos. Ltda, São Paulo, SP, Brasil) bem como o alívio da região anterior inferior entre as raízes dos caninos (Figura 4-A), as moldeiras individuais foram confeccionadas em resina acrílica ativada quimicamente - RAAQ (JET Clássico, São Paulo, SP, Brasil). 
Figura 3 - Moldes anatômicos. A) Molde superior; B) Molde inferior.

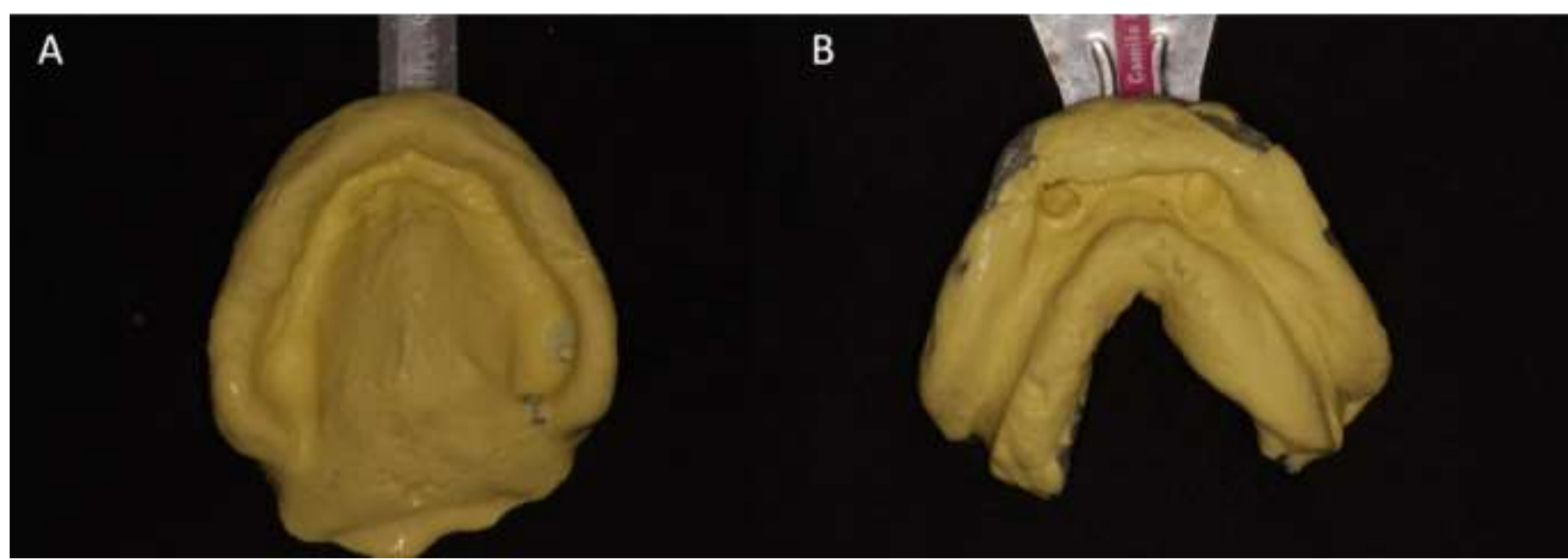

Fonte: Autores.

A moldagem funcional foi realizada de forma distinta para maxila e mandíbula, devido a presença das raízes dos caninos inferiores, por se tratar de estruturas retentivas. Para a maxila, foi utilizado pasta zinco-eonólica (Lysanda - Lysanda Prod. Odontológicos. Ltda, São Paulo, SP, Brasil) para a moldagem de toda a área basal (Figura 4-B), e, para mandíbula, foi utilizado godiva na moldagem do selado periférico (Lysanda Prod. Odontológicos. Ltda, São Paulo, SP, Brasil) e silicone de condensação fluido na moldagem total (Perfil -Vigodent SA Industria e Comércio, Rio de Janeiro, RJ, Brasil) (Figura 4-C). Após desinfecção dos moldes com hipoclorito 1\%, foram confeccionados os modelos de trabalho com gesso pedra especial tipo IV Durone (Dentsply Sirona, São Paulo, Brasil) e sobre eles, a base de prova com os planos de orientação.

Figura 4 - A) Modelo de estudo delimitado com a região anterior e as raízes residuais recobertas com cera 7 para promoção de alívio; B) Molde funcional com pasta zinco enólica do arco superior; C) Molde funcional com godiva e silicone de condensação fluido do arco inferior.

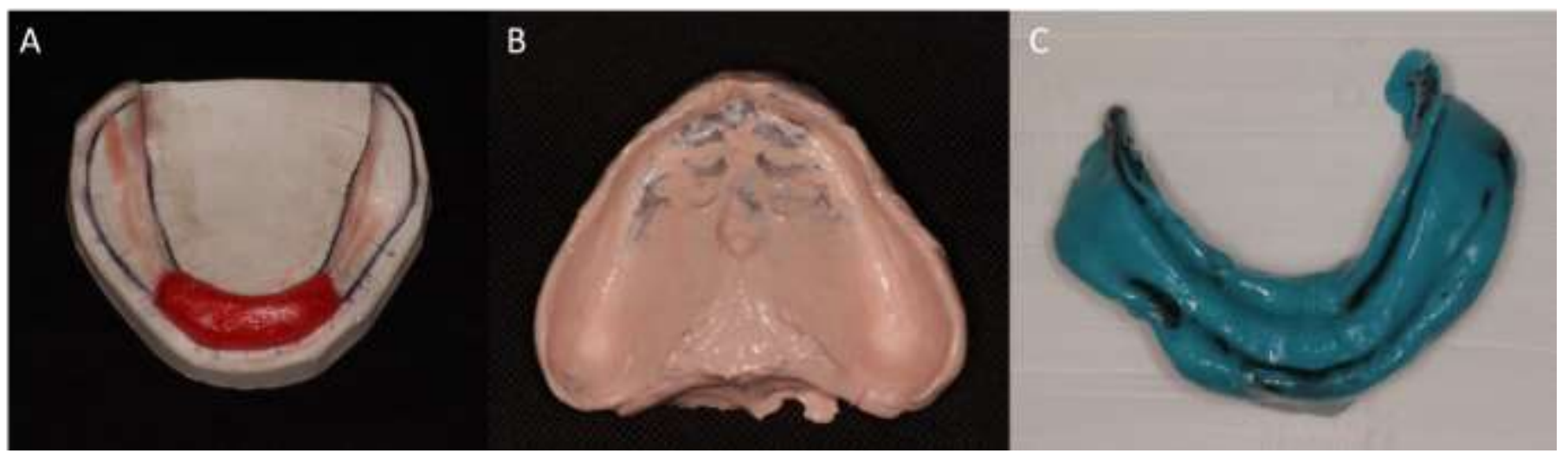

Fonte: Autores.

Posteriormente, foi executada a individualização do plano de orientação superior (Figura 5), seguida do registro da DVO e registro das relações intermaxilares, com a finalidade de obter o padrão oclusal da futura prótese, além das referências estéticas do paciente. A fixação dos planos de orientação, para manutenção dos parâmetros das relações intermaxilares e reprodução dos mesmos na montagem em Articulador Semi Ajustável - ASA foi realizada por meio da confecção de canaletas no plano de cera superior e ranhuras no plano de cera inferior e a interposição de silicone de condensação fluido, sendo o paciente guiado para relação cêntrica. Os modelos foram montados em ASA com mesa de Camper (BioArt, São Carlos, Brasil) 
(Figura 6). A seleção de dentes seguiu as seguintes características: formato do rosto, características físicas, formato do rebordo alveolar, gênero e idade.

Figura 5 - Ajustes do plano de orientação superior. A) Vista aproximada do paciente em repouso com plano de orientação superior em boca; B) Vista aproximada do paciente realizando sorriso forçado com plano de orientação superior em boca; C) Checagem do paralelismo do plano incisal com o plano bipupilar por meio do esquadro de Fox.

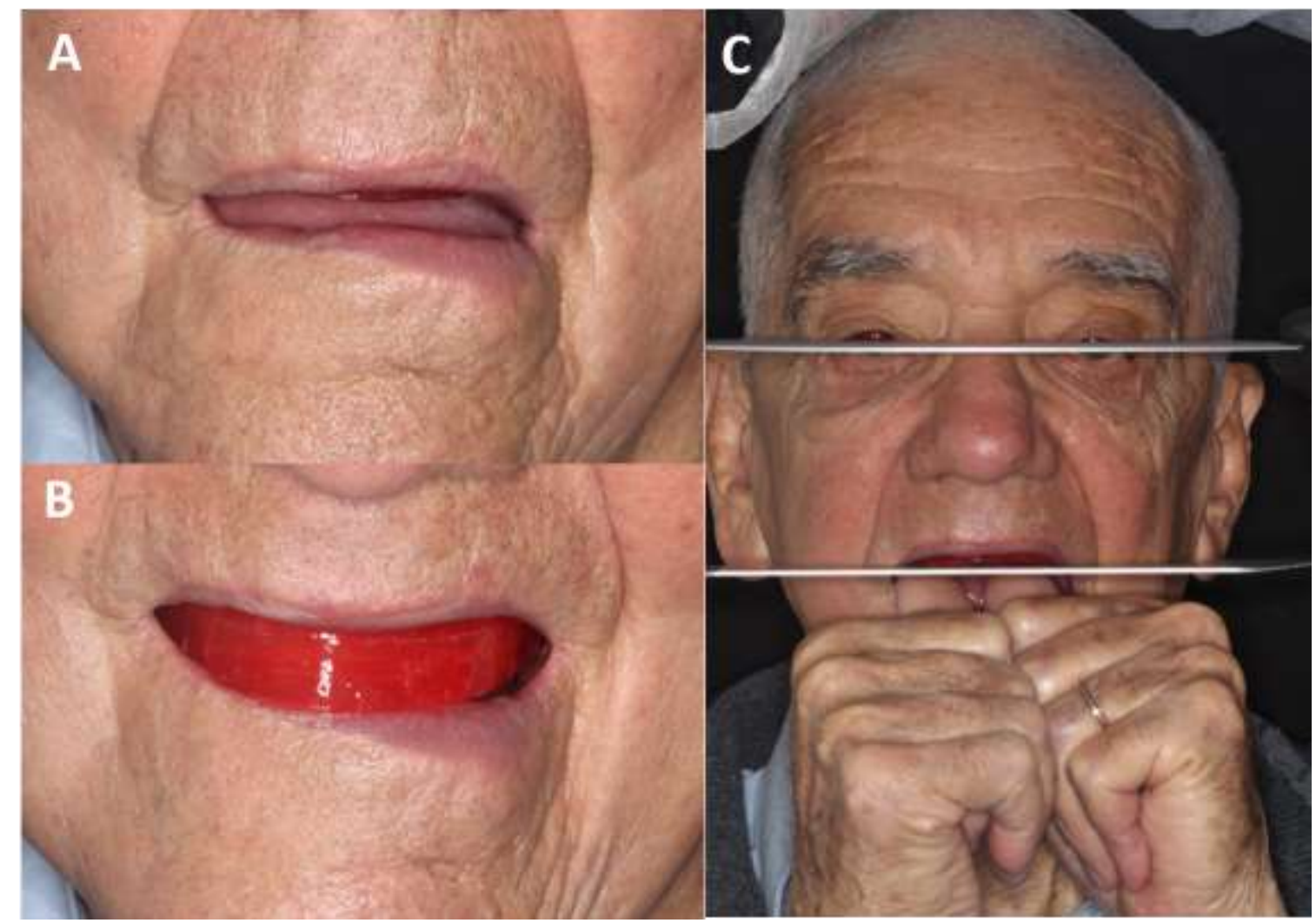

Fonte: Autores. 
Figura 6 - Registro intermaxilar e montagem em ASA. A) Planos de orientação devidamente ajustados em boca prontos para o registro intermaxilar; B) Planos de orientação montados em ASA.

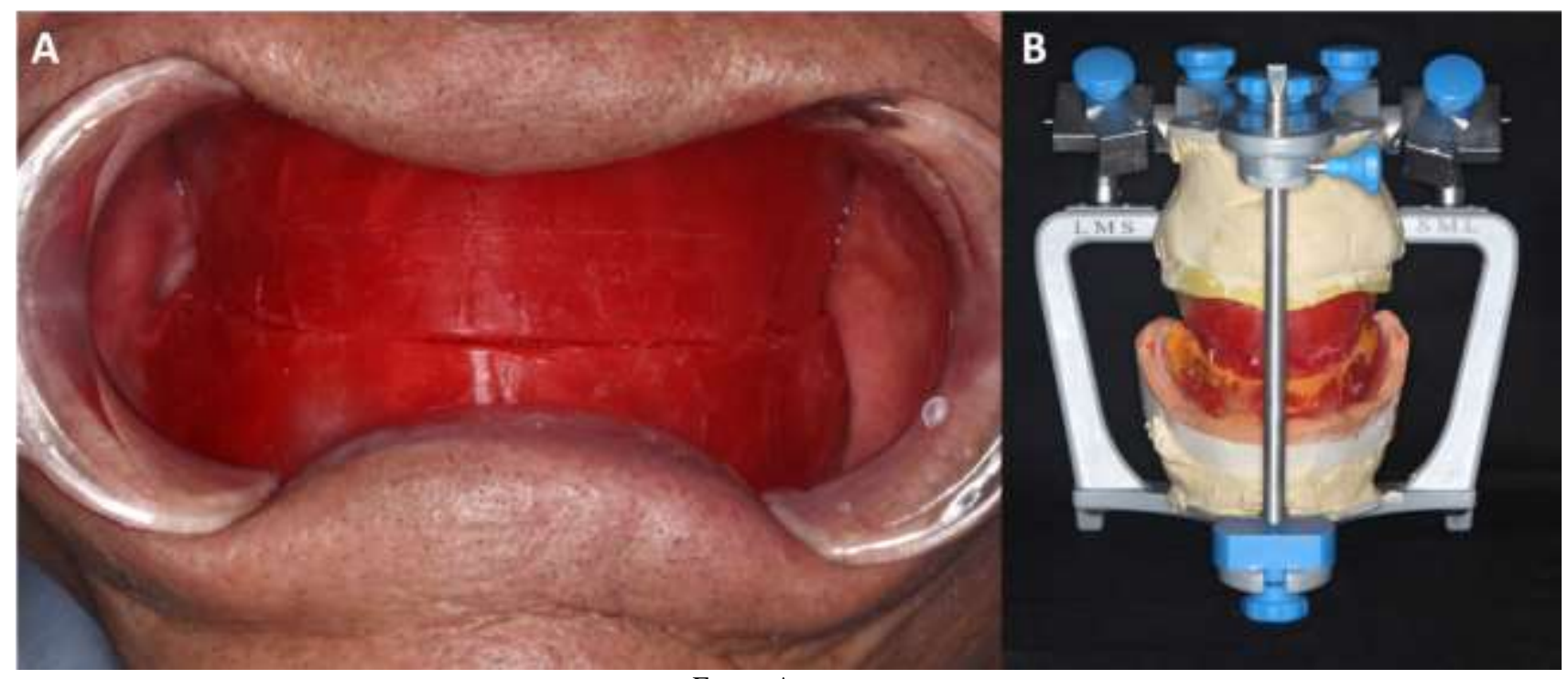

Fonte: Autores.

Após a montagem dos dentes e ceroplastia (Figura 7- A e B), foi feita a prova funcional e estética dos dentes em cera, em que se analisou suporte de lábio, altura incisal, coincidência de linhas médias, linha do sorriso, posição dos dentes, corredor bucal, cor dos dentes, inclinação do plano oclusal, oclusão em relação cêntrica, além da avaliação da dimensão vertical, por meio de testes fonéticos e estéticos (Figura $7-\mathrm{C}$ e D). Após a aprovação por parte do paciente, as próteses foram enviadas ao laboratório para o processo de acrilização.

Figura 7 - Montagem de dentes e prova estética e funcional da montagem de dentes. A) Vista aproximada da montagem de dentes; B) Vista frontal do paciente em repouso com as próteses não acrilizadas em boca; C) Vista frontal do paciente sorrindo com as próteses não acrilizadas em boca.

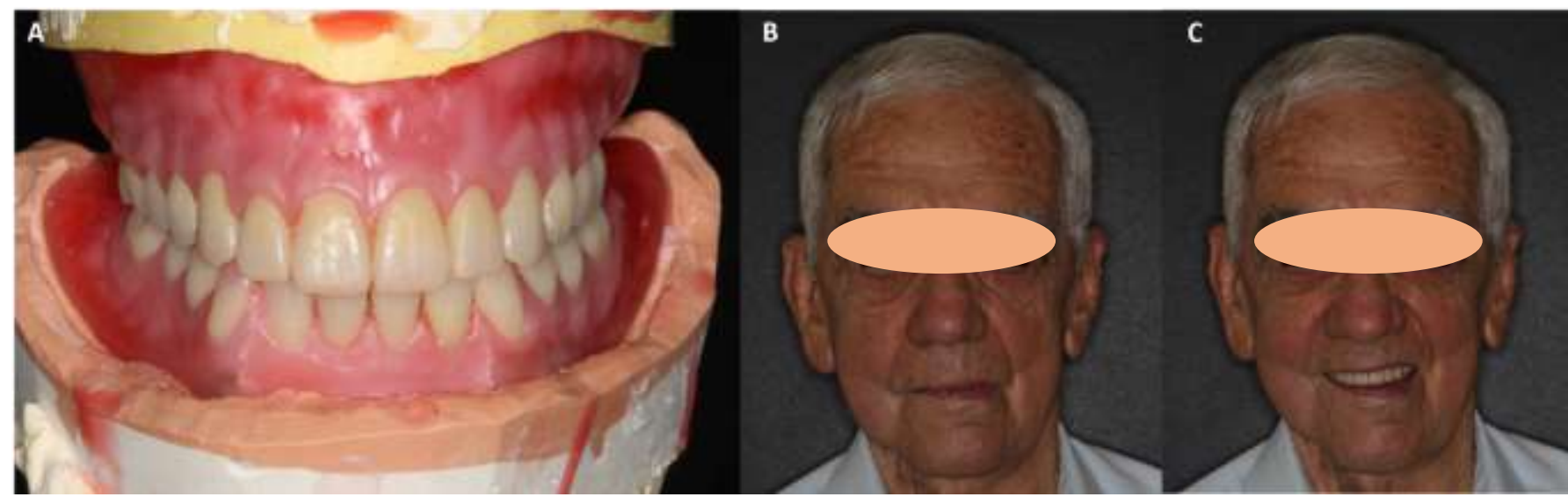

Fonte: Autores.

As próteses foram instaladas com apoio total mucoso, sem contato com as raízes residuais (Figura 8). O paciente as utilizou por 30 dias para acomodação dos tecidos. Nesse período, foram feitos os controles para os ajustes necessários. Quando o paciente relatou ausência de trauma, com estabilidade e conforto, procedeu-se a confecção dos núcleos metálicos fundidos com sistema de retenção de precisão Equator (Neodent, Curitiba, SC, Brasil). 
Figura 8 - Próteses instaladas, sem o sistema de retenção. A) Vista frontal do paciente em repouso; B) Vista frontal do paciente sorrindo; C) Vista lateral do paciente em repouso com próteses em boca evidenciando a recuperação do terço inferior da face; D) e E) Demarcação dos contatos oclusais nas próteses no dia da instalação.

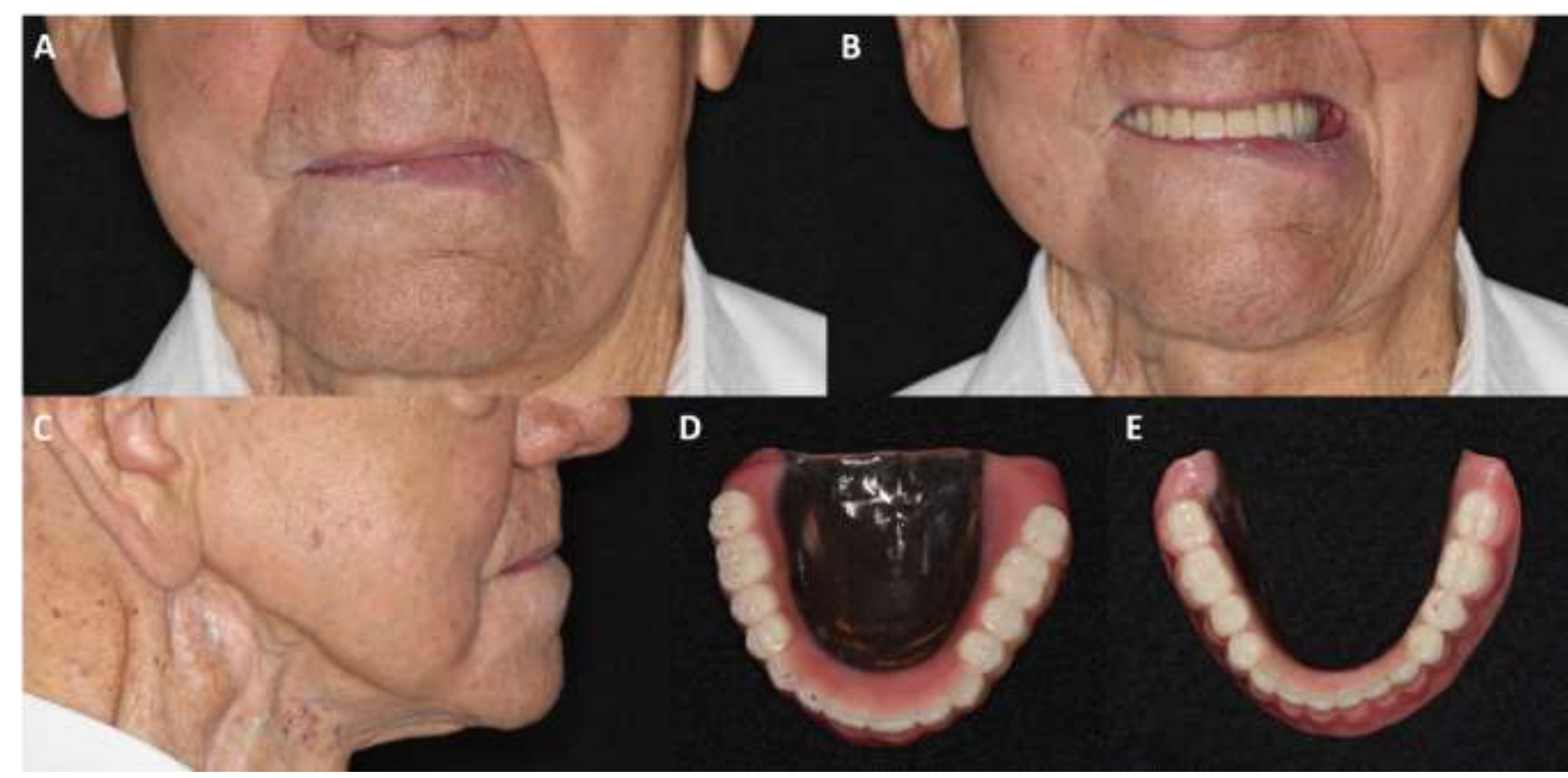

Fonte: Autores.

As raízes dentais dos dois caninos inferiores foram aliviadas utilizando brocas Gates Glidden e Largo e moldadas diretamente com padrão de resina acrílica (Pinjet - Angelus Indústria de Produtos Odontológicos S/A, Londrina, PR, Brasil) e resina acrílica autopolimerizável vermelha Duralay (Reliance, São Paulo, Brasil) para a confecção dos núcleos metálicos fundidos ao attachment Equator (Neodent, Curitiba, SC, Brasil) (Figura 9-A). Foi realizada moldagem de transferência dos núcleos (Figura 9-B) e confecção de um modelo de trabalho (Figura 9- C e D). Com o modelo inferior no delineador, os retentores esféricos do tipo Equator (Neodent, Curitiba, SC, Brasil) foram incorporados ao núcleo de resina de forma que estes ficassem paralelos entre si (Figura $9-\mathrm{E}, \mathrm{F}, \mathrm{G}, \mathrm{H}$ ) e em seguida, foram fundidos (Figura 10). 
Figura 9 - A) Padrão de resina Duralay dos condutos radiculares; B) Moldagem de transferência dos padrões Duralay dos canais radiculares; C) Modelo de trabalho evidenciando os orifícios dos canais radiculares; D) Padrões de Duralay posicionados no modelo de trabalho; E) Recorte da retenção adicional dos padrões de Duralay; F) Equators; G) Posicionamento dos Equators com delineador; H) Equators posicionados sobre padrões de duralay com auxílio do delineador.

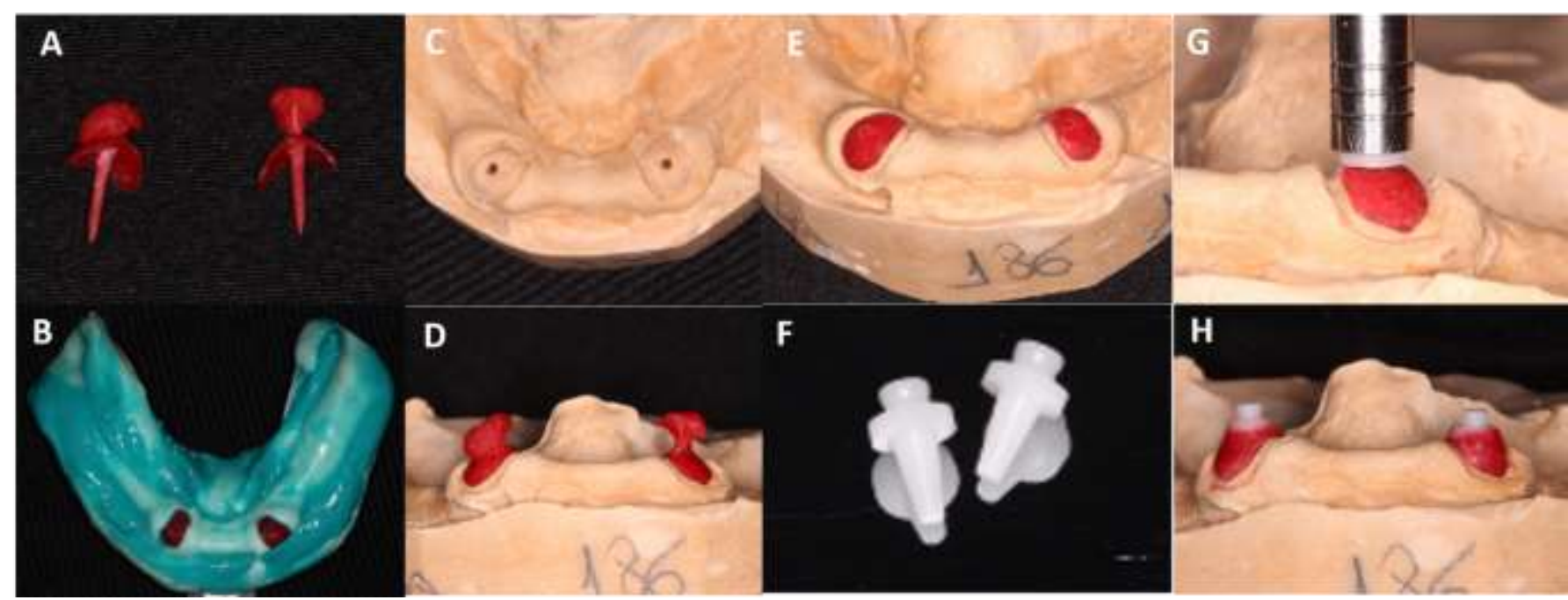

Fonte: Autores.

Figura 10 - A) Equator fundidos ao pino metálico; B) Vista vestibular dos Equators fundidos posicionados no modelo de trabalho; C) Vista lingual dos Equators fundidos posicionados no modelo de trabalho.

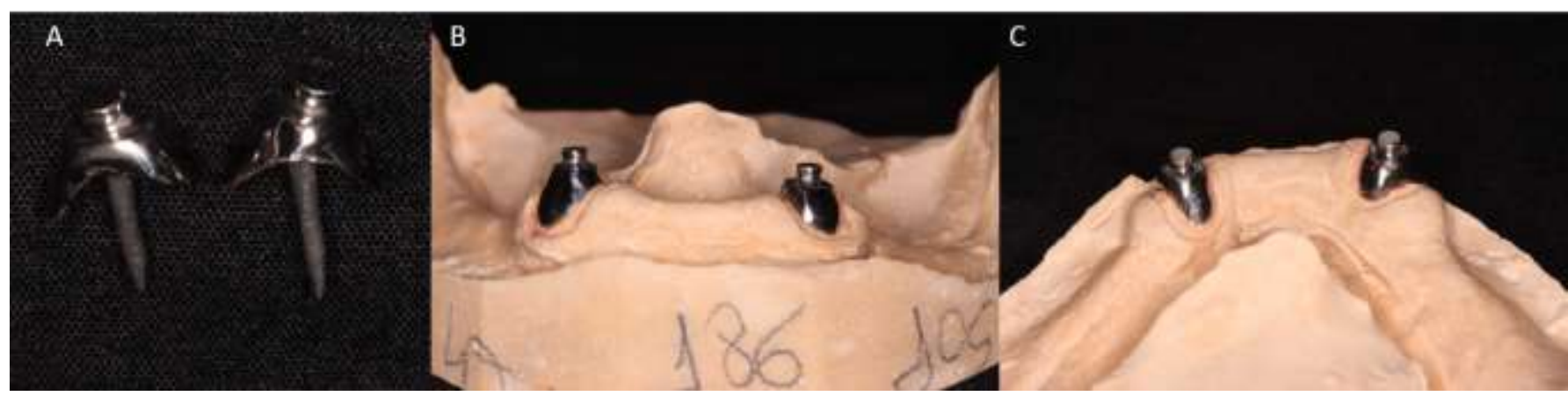

Fonte: Autores.

Após a prova dos componentes metálicos, foi realizada a cimentação destes no interior do canal radicular com cimento resinoso dual autoadesivo (U200 - 3MESPE, Sumaré, Brasil) (Figura 11- A e B). No interior da prótese total inferior, foram realizados alívios na região dos retentores para captura das cápsulas metálicas. As cápsulas metálicas do attachment foram encaixadas nos retentores e resina acrílica foi colocada sobre estes e no interior do alívio realizado na prótese e a mesma foi levada à boca do paciente. Solicitou-se ao paciente que mantivesse as próteses em oclusão, alertando o paciente sobre não exercer pressão exagerada, apenas o suficiente para manter os dentes em contato até a presa da resina acrílica. Após a polimerização da RAAQ, retirou-se a prótese da boca do paciente e procedeu-se o preenchimento de eventuais espaços vazios entre as cápsulas metálicas e a base da prótese (Figura $11-\mathrm{C}$ e D). Realizou-se o acabamento da região da captura e conferência da oclusão das próteses, atentando-se a arredondar a aresta aguda da região cervical, com objetivo de promover um alívio que impede o contato direto da resina da base com os tecidos periodontais, evitando irritação mecânica que pode gerar desconfortos e trauma gengival, que deve ser bastante evitado em pacientes irradiados. Orientações de uso e de higienização foram passadas ao paciente. 
Nos casos de pacientes irradiados na região de cabeça e pescoço o reforço das orientações quanto a remoção temporária da prótese caso esta esteja machucando até o próximo retorno ao consultório é de extrema importância, para que úlceras traumáticas não se desenvolvam, uma vez estas podem levar ao desenvolvimento de osteorradionecrose. Deve-se salientar também os cuidados com a higienização, pois a cárie relacionada a radiação que destruiu as coroas dos caninos pode se desenvolver ao redor da adaptação dos copings metálicos com as raízes destes elementos dentais, levando a perda das raízes envolvidas no suporte e retenção da overdenture inferior. E ainda, instruções quanto ao aumento na ingestão de água para favorecer uma melhor manutenção da umidade da cavidade bucal, prevenindo, assim, maior atrito entre a base e mucosa em relação à pequena quantidade de saliva que o paciente irradiado pode apresentar.

A captura do clip de retenção promove maior retenção e estabilidade, reduzindo a pressão e o movimento da prótese sobre a mucosa, diminuindo atritos e traumas, o que promove maior conforto no uso. Desta forma, nas visitas de controle posterior, o paciente relatou conforto ao utilizar as próteses, apresentando controle da força mastigatória e melhor percepção da textura e tamanho do alimento mastigado, o que aumentou a performance em todos os aspectos funcionais, como digestão e fala (Figura 12). Foi enfatizado ao paciente a necessidade de retornos frequentes para avaliação da mucosa, remanescentes dentais e da prótese (necessidade de substituição da borracha do anel de retenção ou de reembasamento das próteses).

Figura 11 - A) Vista vestibular dos Equators fundidos cimentados; B) Vista oclusal dos Equators fundidos cimentados; C) Vista da base da prótese total inferior após a captura do housing metálico dos Equators; D) Vista aproximada da captura do housing metálico dos Equators na base da prótese total inferior.

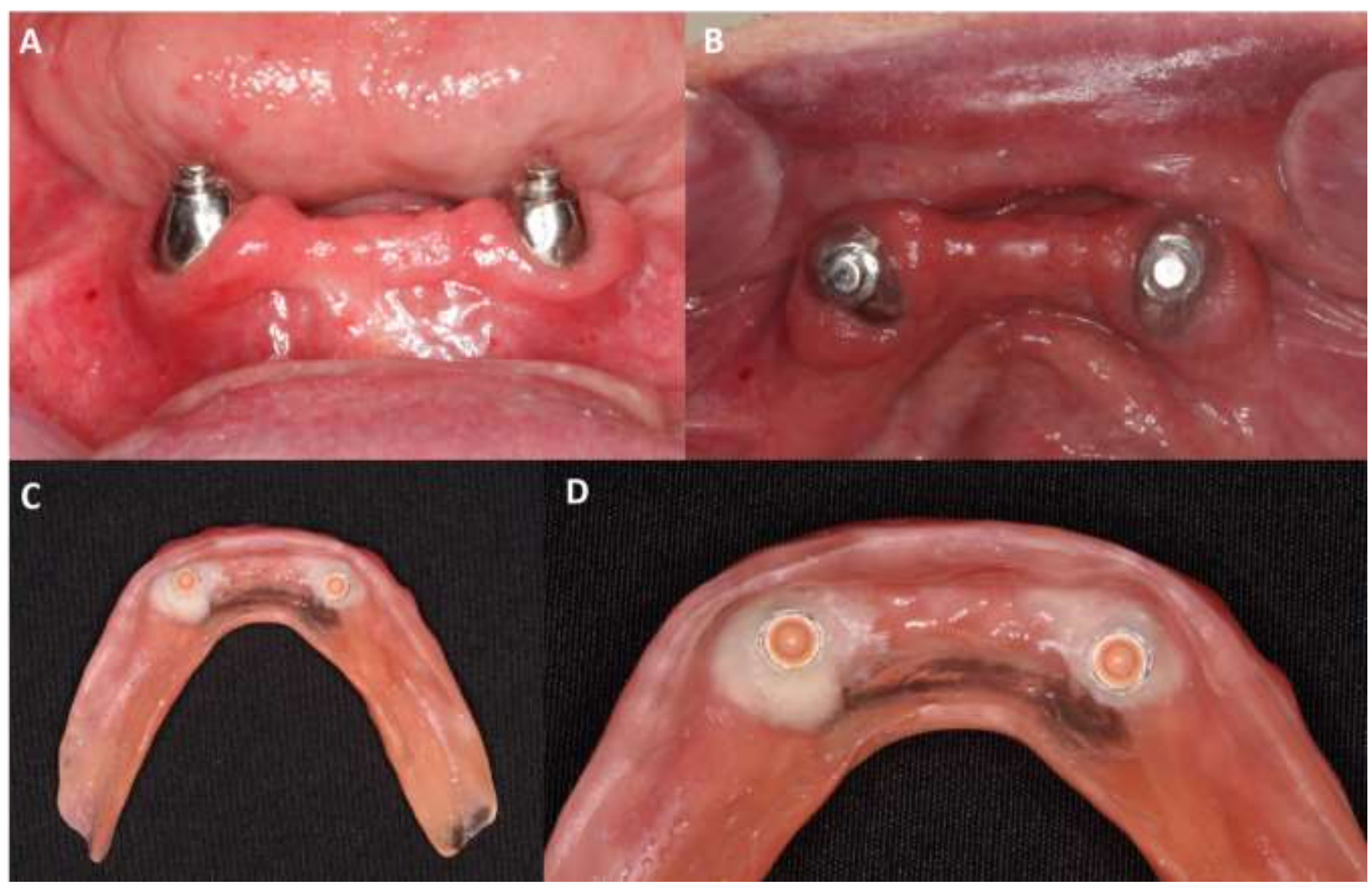

Fonte: Autores.

Figura 12 - Vista frontal do paciente com as próteses em boca após a instalação e captura dos o’rings. 
Research, Society and Development, v. 10, n. 7, e48010716739, 2021

(CC BY 4.0) | ISSN 2525-3409 | DOI: http://dx.doi.org/10.33448/rsd-v10i7.16739

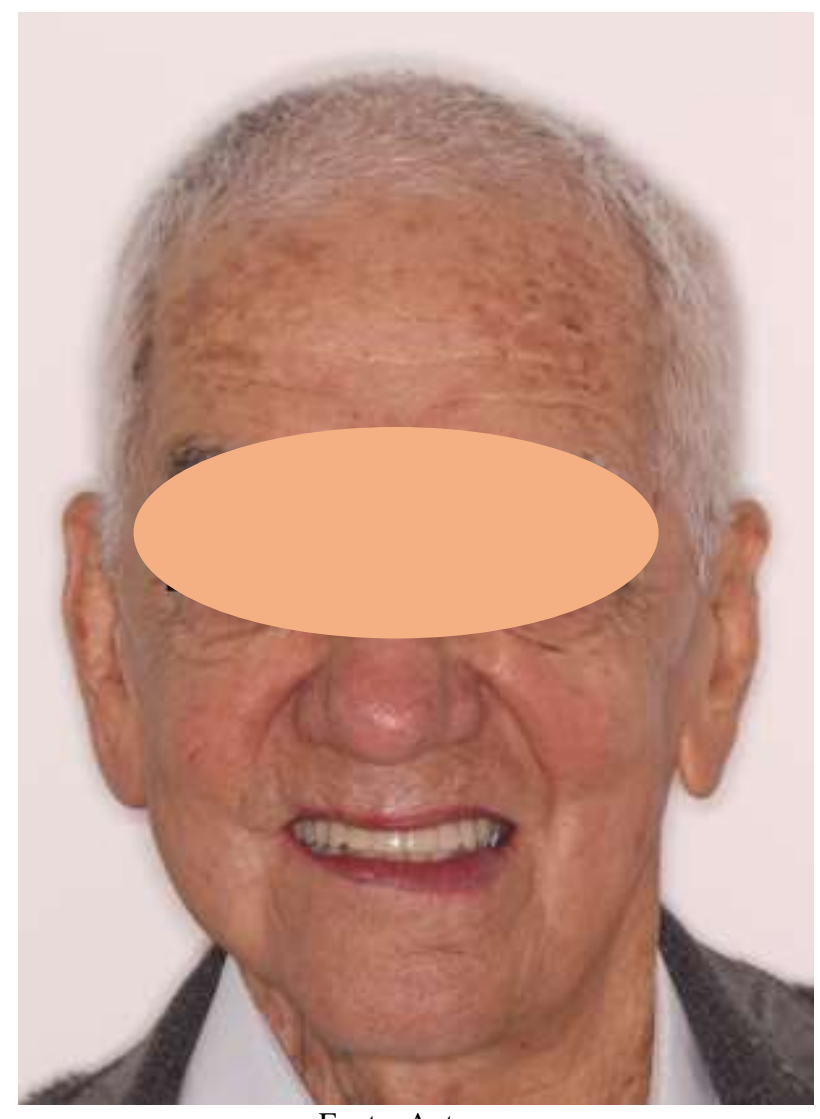

Fonte: Autores.

Figura 13 - Foto do antes e depois do paciente reabilitado com prótese total superior e overdenture inferior, evidenciando a melhora do plano oclusal e melhora do aspecto estético do terço inferior da face do paciente.
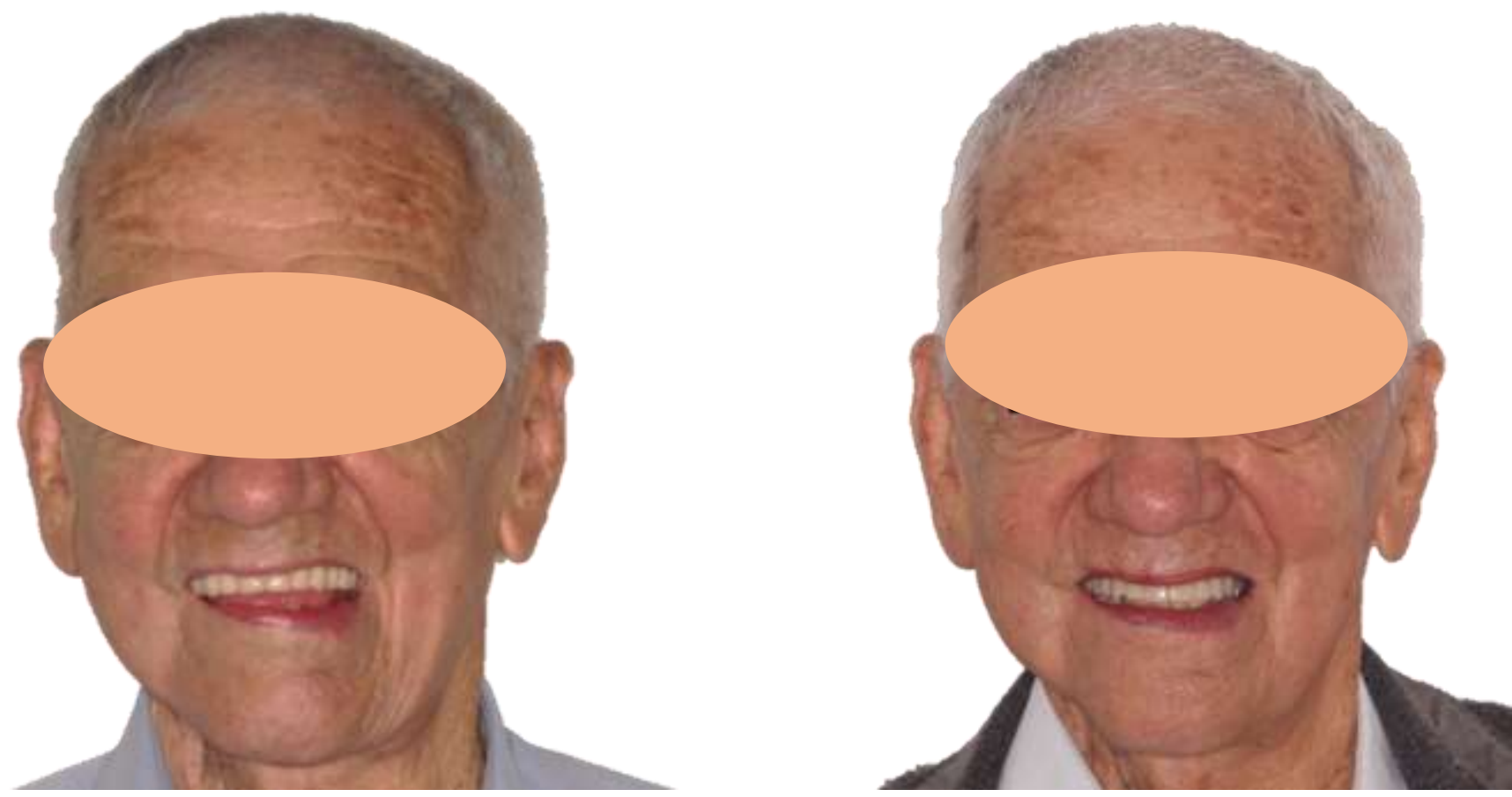

Fonte: Autores. 


\section{Discussão}

Em geral, grande parte dos pacientes portadores de prótese total convencional mandibular relatam insatisfação quanto a sua pouca retenção e estabilidade, o que acaba diminuindo assim a sua capacidade mastigatória, autoconfiança, autoestima e convívio social (Novaes \& Seixas, 2008). Em pacientes que passaram pelo tratamento para o câncer, as consequências da radioterapia tornam esta situação clínica ainda mais desafiadora (Petrovic et al., 2018). A radiação ionizante causa danos aos vasos sanguíneos do osso, levando à hipóxia do tecido e aumentando a risco à osteorradionecrose em situações de trauma, como pode ocorrer no uso de prótese removível (Fromm et al., 2019; Petrovic et al., 2018). Somado a isto, a hipossalivação decorrente da radiação às glândulas salivares, consequente xerostomia, dor e mucosites limitam o uso de próteses pelos pacientes (Bhandari et al., 2020). Cirurgias de instalação de implantes que poderiam favorecer a estabilidade e retenção dessas próteses também devem ser evitadas devido ao risco de osteorradionecrose (Kawashita et al., 2020; Petrovic et al., 2018). Portanto, procedimentos atraumáticos como a confecção de overdenture sobre raízes é uma alternativa possível e viável, e que devem sempre ser pensadas.

A influência da radioterapia sobre as glândulas salivares, ossos, estruturas dentais e mucosas interfere diretamente na utilização de próteses removíveis pelos pacientes oncológicos pós radioterapia (Fromm et al., 2019; Petrovic et al., 2018). A cárie relacionada à radiação ionizante é caracterizada por rápida progressão, aspecto clínico e de desenvolvimento diferente da cárie convencional. Inicialmente, pode apresentar alterações de cor e translucidez das coroas, sendo a região cervical a área mais afetada (Palmier et al., 2020). Além disso, pode levar à delaminação do esmalte e fraturas, comprometendo toda a coroa dentária (Palmier et al., 2020). Essa condição foi percebida neste caso clínico, no qual os dentes inferiores apresentavam-se cariados e com grande destruição coronária, o que comprometeu a retenção da prótese parcial removível usada pelo paciente.

Neste caso clínico, optou-se por manter as raízes dos elementos dentais 33 e 43 e utilizá-las como retentores para a instalação de uma prótese do tipo overdenture, permitindo uma melhor retenção e estabilidade às próteses removíveis e maior conforto ao paciente (Petrovic et al., 2018). A prótese do tipo overdenture corresponde a uma prótese dentária removível mucossuportada retida sobre dispositivos, como implantes osseointegrados ou retentores cimentados em raízes remanescentes, sendo esta última a opção realizada no caso clínico aqui descrito. A reabilitação oral com auxílio de sistemas de retenção adicional em próteses totais removíveis garante melhora considerável na mastigação e deglutição dos alimentos, na possibilidade de adotar uma dieta melhor, na absorção dos nutrientes, na comunicação e estética, promovendo diretamente o aumento na qualidade de vida (Barret \& Roodenburg, 2017; Fromm et al., 2019; Jain et al., 2012). A prótese executada neste caso clínico, além de apresentar estas vantagens, preservou os remanescentes dentários e suas estruturas de suporte, com redução de carga nas regiões ósseas de suporte da prótese e minimizou o processo de reabsorção, mantendo-os em estado de saúde e função (Chhabra et al., 2019; Miller et al., 1956).

A escolha do sistema de retentores é uma etapa importante no planejamento da prótese overdenture. A seleção deve levar em consideração o posicionamento das raízes dentárias ou implantes, a distância entre eles, o espaço interoclusal e as características anatômicas de cada paciente (Bhargava et al., 2016; Park et al., 2019). Neste caso, optou-se pelo sistema anéis de retenção/O'ring, por ser de simples manutenção e tratando-se de um sistema independente, apresenta maior facilidade de higienização (Bhargava et al., 2016; Dominici et al., 1996; Tokuhisa et al., 2003; van Kampen et al., 2003; Vere et al., 2012). Neste caso em específico, o paralelismo que é exigido para este tipo de sistema foi conseguido no momento de captura do retentor no padrão em resina do núcleo com o uso de delineador.

Um diferencial importante entre os diferentes sistemas de anéis de retenção refere-se à altura do perfil do pilar. Neste caso clínico, o paciente apresentava rebordo alveolar inferior anterior alto, gerando espaço intermaxilar reduzido. Normalmente, o espaço necessário para captura de um sistema de retenção em próteses removíveis sobre raízes é maior do que o necessário para próteses removíveis sobre implantes (Costa et al., 2001). Além disso, o desgaste na parte interna da base 
pode se estender em direção à borda da prótese, devido ao volume da bossa da raiz do dente, principalmente na região de caninos, onde este volume é mais acentuado. Por isso, um pilar que requer uma pequena altura e pequeno volume geraria um alívio interno menor, o que deixa a prótese com maior resistência às forças e tensões geradas pela mastigação e hábitos, reduzindo a probabilidade de fratura (Costa et al., 2001). Desta forma, selecionou-se o sistema Equator da Neodent, pois o mesmo exige um espaço para captura reduzido de $2,1 \mathrm{~mm}$, ao passo que o sistema O'ring requer um espaço de captura de 4.0mm (Neodent - Straumann, 2016).

Dentre as possíveis intercorrências na reabilitação com sistemas de retenção sobre remanescentes dentários, podem ser observadas inflamações gengivais ao redor dos elementos pilares e cárie dentária (Chhabra et al., 2019). A prática deficiente da higiene oral é um fator importante a ser considerado nos pacientes reabilitados com overdenture sobre raízes, visto que a presença de biofilme pode levar a quadros clínicos de gengivite e periodontite (Chhabra et al., 2019). E se tratando de pacientes submetidos à radioterapia, deve-se levar em consideração que grande parte das perdas dentárias se dá devido ao desenvolvimento da cárie relacionada à radiação (Palmier et al., 2020). Portanto, é recomendado um monitoramento frequente, sempre observando as necessidades de higiene oral do paciente, a fim de prevenir e diagnosticar a cárie em estágios iniciais (Palmier et al., 2020).

Buscar estratégias de prevenção da cárie relacionada à radiação é crucial para a saúde oral do paciente e sucesso do tratamento reabilitador (Kawashita et al., 2020; Palmier et al., 2020). O ambiente oral permanece alterado mesmo após o término do tratamento radioterápico, sendo a diminuição da saliva o principal fator de risco de desenvolvimento da cárie, além da dificuldade de higienização e a estrutura dental que se encontra comprometida pela radiação de forma definitiva (Bhandari et al., 2020; Kawashita et al., 2020; Lu et al., 2019; Miranda et al., 2019; Moore et al., 2020; Noone et al., 2017; Rodrigues et al., 2018). Desta forma, a diminuição do fluxo salivar associada à estrutura dental afetada pela radiação ionizante aumentam a progressão da cárie (Lopes et al., 2021). Somado a isto, a cárie relacionada à radiação apresenta desenvolvimento rápido e agressivo, podendo levar a perda da dentição em um curto período de tempo. Portanto, o acompanhamento periódico destes pacientes é muito importante para a avaliação e manutenção dos dentes (Noone et al., 2017; Moore et al., 2020; Palmier et al., 2020). A aplicação de flúor é uma estratégia eficiente para aumentar a resistência à cárie relacionada à radiação, fornecendo benefícios na prevenção e remineralização da estrutura dental (Kawashita et al., 2020; Lopes et al., 2018; Noone et al., 2017; Palmier et al., 2020) Além do risco de ocorrência da cárie, é importante atentar-se à adaptação adequada da prótese e qualidade dos retentores, para evitar traumas à mucosa que é um fator de risco à osteorradionecrose (Petrovic et al., 2018). Desta forma, o acompanhamento destes pacientes deve ser realizado ao longo de sua vida, mesmo após o término do tratamento antineoplásico, sendo imprescindível para evitar insucessos.

A literatura acerca da reabilitação oral de pacientes com câncer na região de cabeça e pescoço ainda é escassa, e os cirurgiões-dentistas devem ter conhecimento das dificuldades envolvidas no tratamento bucal destes pacientes (Fromm et al., 2019). É necessário o acompanhamento longo e periódico dos casos. As diversas alterações decorrentes da radioterapia sobre a cavidade oral tornam a reabilitação destes pacientes bastante desafiadora. Portanto, relatar e discutir sobre esta temática é de extrema relevância para o conhecimento dos profissionais.

\section{Conclusão}

A reabilitação oral de pacientes com história clínica de neoplasias da de cabeça e pescoço exige atenção especial e condução criteriosa. As próteses overdenture sobre raízes associadas ao sistema de anéis de retenção Equator devolveram as funções estética, fonética e mastigatória, promovendo melhora da qualidade de vida e um melhor convívio social ao paciente.

Mais estudos acerca da reabilitação oral deste grupo de pacientes são necessários. Estudos clínicos devem ser realizados a respeito da manutenção e longevidade deste tipo de reabilitação protética pacientes irradiados. 


\section{Agradecimentos}

Ao programa de extensão de Suporte Odontológico Preventivo e Restaurador ao Paciente portador de Neoplasia Maligna sob Tratamento Oncológico (SOPRO), ao Programa de Cuidados Especiais a Doenças Estomatológicas (Procede), ao projeto de extensão Overdenture para desdentados totais na geriatria da Escola Técnica de Saúde da Universidade Federal de Uberlândia e à Fundação de Amparo à Pesquisa do Estado de Minas Gerais (FAPEMIG).

\section{Referências}

Barret, J. P. \& Roodenburg, J. L. (2017). Functional rehabilitation in advanced intraoral cancer. Int J Surg Oncol (NY), 2(2), 10. Bhandari, S., Soni, B. W., Bahl, A. \& Ghoshal, S. (2020). Radiotherapy-induced oral morbidities in head and neck cancer patients. Special Care in Dentistry, 40(3), 238-250.

Bhargava, A., Sehgal, M., Gupta, S. \& Mehra, P. (2016). Classification system on the selection of number of implants and superstructure design on the basis available vertical restorative space and interforaminal distance for implant supported mandibular overdenture. J Indian Prosthodont Soc, 16, $131-135$.

Bray, F., Ferlay, J., Soerjomataram, I., Siegel, R. L., Torre, L. A., \& Jemal, A. (2018). Global cancer statistics 2018: GLOBOCAN estimates of incidence and mortality worldwide for 36 cancers in 185 countries. CA Cancer J Clin, 68(6):394-424.

Bueno, A. C., Magalhães, C. S. \& Moreira, A. N. (2012). Associações entre Fatores de Risco e Complicações Bucais em Pacientes com Câncer de Cabeça e Pescoço Tratados com Radioterapia Associada ou não à Quimioterapia. Pesq Bras Odontoped Clin Integr, 12(2), $187-193$.

Chhabra, A., Chhabra, N., Jain, A. \& Kabi, D. (2019). Overdenture Prostheses with Metal Copings: A Retrospective Analysis of Survival and Prosthodontic Complications. J Prosthodont, 28(8), 876-882.

Chronopoulos, A., Zarra, T., Ehrenfeld, M. \& Otto, S. (2018). Osteoradionecrosis of the jaws: definition, epidemiology, staging and clinical and radiological findings. A concise review. Int Dent J, 68(1), 22-30.

Costa, M. M. et al. (2001). Overdentures sobre raízes dentais - revisão da literatura. ABO - revista da Associação Brasileira de Odontologia, 8(56), 8-9.

Dominici, J. T., Kinderknecht, K. E. \& Patella-Clark, E. (1996). Clinical procedure for stabilizing and connecting O-ring attachments to a mandibular implant overdenture. J Prosthet Dent, 76(3), 330-333.

Dudic, A. \& Mericske-Stern, R. (2002). Retention mechanisms and prosthetic complications of implant-supported mandibular overdentures: long-term results. Clin Implant Dent Relat Res, 4(4), 212-9.

Fromm, L., Gotfredsen, K., Wessel, I. \& Øzhayat, E. B. (2019). Oral health-related quality of life, oral aesthetics and oral function in head and neck cancer patients after oral rehabilitation. J Oral Rehabil, 46(8), 738-746.

Gonçalves, L. M., Palma-Dibb, R. G., Paula-Silva, F. W., Oliveira, H. F., Nelson-Filho, P., Silva, L. A. \& Queiroz, A. M. (2014). Radiation therapy alters microhardness and microstructure of enamel and dentin of permanent human teeth. Journal of Dentistry, 42(8), 986-92.

INCA, Instituto Nacional de Câncer José Alencar Gomes da Silva. (2019). Estimativa 2020: incidência de câncer no Brasil. https://www.inca.gov.br/estimativa/estado-capital/brasil

Jain, M., Kaira, L. S., Sikka, G., Singh, S., Gupta, A., Sharma, R., Sawla, L. \& Mathur, A. (2012). How do age and tooth loss affect oral health impacts and quality of life? A study comparing two state samples of gujarat and rajasthan. J Dent (Tehran), 9(2), 135-144.

Jham, B. C. \& Freire, A. R. S. (2006). Complicações bucais da radioterapia em cabeça e pescoço. Rev. Bras. Otorrinolaringol, 72(5).

Kawashita, Y., Soutome, S., Umeda, M. \& Saito, T. (2020). Oral management strategies for radiotherapy of head and neck cancer. Jpn Dent Sci Rev, 56(1):6267.

Langlois, E., Desaeyer, H., Petrovic, M., Van Lierde, K. \& De Visschere, L. (2019). The influence of oral health status on speech intelligibility, articulation and quality of life of older community-dwelling people. Gerodontology, 36(4), 352-357.

Lopes, C. C. A., Rodrigues, R. B., Cenci, M. S., Uehara, J. L. S., Maske T. T., Limirio P. H. J. O., Soares, P. B. F., Novais, V. R. (2021) Effect of ionizing radiation and cariogenic biofilm challenge on root-dentin caries. Clin Oral Investig.

Lopes, C. C. A., Soares, C. J., Lara, V. C., Arana-Chavez, V. E., Soares, P. B. \& Novais, V. R. (2018). Effect of fluoride application during radiotherapy on enamel demineralization. Journal of Applied Oral Science, 27.

Lu, H., Zhao, Q., Guo, J., Zeng, B., Yu, X., Yu, D. \& Zhao, W. (2019) Direct radiation-induced effects on dental hard tissue. Radiation Oncology, 14 (1), 5.

Miranda, R. R., Ribeiro, T. E., Silva, E. L. C. D., Simamoto Júnior, P. C., Soares, C. J., Novais, V. R. (2021) Effects of fractionation and ionizing radiation dose on the chemical composition and microhardness of enamel. Arch Oral Biol.

Miranda, R. R., Silva, A. C. A., Dantas, N. O., Soares, C. J. \& Novais, V. R. (2019) Chemical analysis of in vivo-irradiated dentine of head and neck cancer patients by ATR-FTIR and Raman spectroscopy. Clinical Oral Investigations, 23(8), 3351-3358.

Miller, P.A. (1958). Complete dentures supported by natural teeth. J Pros Den, 8(6), 924-928. 
Moore, C., McLister, C., Cardwell, C., O'Neill, C., Donnelly, M. \& McKenna, G. (2020) Dental caries following radiotherapy for head and neck cancer: A systematic review. Oral Oncology, 100, 104484.

Montserrat, V.L., Gerry, O., Hagiwara, M. \& Sonis, S. (2006). Oral mucositis in patients undergoing radiation treatment for head and neck carcinoma. Cancer, 106(2), 329-336.

Müller, V. J., Belibasakis, G. N., Bosshard, P. P., Wiedemeier, D. B., Bichsel, D., Rücker, M. \& Stadlinger, B. (2019) Change of saliva composition with radiotherapy. Archives of Oral Biology, 106:104480.

Neodent - Straumann. (2016). Catálogo Neodent 2016. http://straumann.com.

Noone, J. \& Barclay, C. (2017) Head and Neck Cancer Patients - Information for the General Dental Practitioner. Dental Update, 44 (3), $209-215$

Novaes, L. C. G. F. \& Seixas, Z. A. (2008). Prótese total sobre implante: técnicas contemporâneas e satisfação do paciente. Int J Dent. 7(1), 50-62.

Palmier, N. R., Migliorati, C. A., Prado-Ribeiro, A. C., Vechiato Filho, A. J., de Goes, M. F., Brandão, T. B., Lopes, M. A. \& Santos-Silva, A. R. (2020). Radiation-related caries: current diagnostic, prognostic, and management paradigms. Oral Surg Oral Med Oral Pathol Oral Radiol, 130(1), 52-62.

Park, J. H., Shin, S. W. \& Lee, J. Y. (2019). Bar versus ball attachments for maxillary four-implant retained overdentures: A randomized controlled trial. Clin Oral Implants Res, 30(11), 1076-1084.

Pereira, A. S., Shitsuka, D. M., Parreira, F. J. \& Shitsuka, R. (2018). Metodologia da pesquisa científica. https://repositorio.ufsm.br/bitstream/handle/1/15 824/Lic_C omputacao_Metodologia-Pesquisa-Cientifica.pdf?sequence=1

Petrovic, I., Rosen, E. B., Matros, E., Huryn, J.M. \& Shah, J. P. (2018). Oral rehabilitation of the cancer patient: A formidable challenge. J Surg Oncol, 117(8), $1729-1735$.

Reed, R., Xu, C., Liu, Y., Gorski, J. P., Wang, Y. \& Walker, M. P. (2015). Radiotherapy effect on nano-mechanical properties and chemical composition of enamel and dentine. Archives of Oral Biology, 60(5), 690-7.

Rodrigues, R. B., Soares, C. J., Junior, P. C. S., Lara, V. C., Arana-Chavez, V. E. \& Novais, V. R. (2018). Influence of radiotherapy on the dentin properties and bond strength. Clinical Oral Investigations, 22(2), 875-883.

Schoen, P.J., Raghoebar, G.M., Bouma, J., Reintsema, H., Vissink, A., Sterk, W. \& Roodenburg, J. L. (2007). Rehabilitation of oral function in head and neck cancer patients after radiotherapy with implant-retained dentures. Oral Oncology, 43, 379-388.

Spetch, L. (2002). Oral complications in the head and neck irradiated patient. Introduction and scope of the problem. Supp Care Dent, 10, 36-39.

Sroussi, H. Y., Epstein, J. B., Bensadoun, R. J., Saunders, D. P., Lalla, R. V., Migliorati, C. A., Heaivilin, N. \& Zumsteg, Z. S. (2017). Common oral complications of head and neck câncer radiation therapy: mucosites, infections, saliva change, fibrosis, sensory dysfuncions, dental caries, periodontal disease, and osteraionecrosis. Cancer Med, 6(12), 2918-2931.

Tokuhisa, M., Matsushita, Y. \& Koyano, K. (2003). In vitro study of a mandibular implant overdenture retained with ball, magnet, or bar attachments: comparison of load transfer and denture stability. Int J Prosthodont, 16(2), 128-134.

van Kampen, F., Cune, M., van der Bilt, A. \& Bosman, F. (2003). Retention and postinsertion maintenance of bar-clip, ball and magnet attachments in mandibular implant overdenture treatment: an in vivo comparison after 3 months of function. Clin Oral Implants Res, (6), 720-726.

Vere, J., Hall, D., Patel, R. \& Wragg, P. (2012). Prosthodontic maintenance requirements of implant-retained overdentures using the locator attachment system. Int J Prosthodont, 25(4), 392-394.

World Health Organization. (2020). Noncommunicable diseases. http://www.who.int/news-room/fact-sheets/detail/noncommunicable-diseases. 